кандидат экономических наук, доцент кафедры финансового менеджмента Российского экономического университета имени Г.В. Плеханова

\section{ПРИВЛЕЧЕНИЕ ФИНАНСОВЫХ РЕСУРСОВ ДЛЯ МАЛЫХ СУБЪЕКТОВ АГРОПРОМЫШЛЕННОГО КОМПЛЕКСА РОССИИ ПОСРЕДСТВОМ КРЕДИТОВАНИЯ PEER-TO-PEER [1]}

\begin{abstract}
Аннотация:
Автор статьи предлагает рассмотреть возможность внедрения в систему финансирования малых форм хозяйствования в российском агропромышленном комплексе альтернативного механизма кредитования peer-to-peer. В процессе исследования выявлены факторы, способствующие использованию подобной технологии кредитования в рамках системы финансирования малых субъектов агропромышленного комплекса Российской Федерации и препятствующие ему. В целом, несмотря на наличие негативных факторов применения способа кредитования peer-to-peer в изучаемой сфере, непреодолимые препятствия для его реализации малыми формами хозяйствования отсутствуют. При этом его преимущества в перспективе способны только привлекать все больше заинтересованных лиц, что обусловлено возможностью получения финансовых ресурсов таким альтернативным способом, каким является кредитование peer-to-peer.

\section{Ключевые слова:}

кредитование peer-to-peer, агропромышленный комплекс, малые формы хозяйствования, финансирование.
\end{abstract}

$\mathrm{PhD}$ in Economics Assistant Professor, Financial Management Department, Plekhanov Russian University of Economics

FUNDRAISING RELATED TO SMALL ENTITIES OF THE RUSSIAN AGRO-INDUSTRIAL COMPLEX BY PEER-TO-PEER LENDING [1]

Summary:

The author considers the possibility of introducing the alternative mechanism, i.e. peer-to-peer lending, into the funding system of small businesses of the Russian agro-industrial complex. The study identifies the factors that facilitate and impede the implementation of this lending technology within the funding system of small business entities of the above-mentioned complex. In general, despite the negative factors of applying peer-to-peer lending mechanism in the studied area, there are no insurmountable obstacles to use it by small businesses. In addition, its benefits will attract more stakeholders in future due to the possibility of funding through such an alternative method as a peerto-peer lending.

Проблема кредитования малых фрорм хозяйствования в агропромышленном комплексе попрежнему остается острой, несмотря на все усилия, прилагаемые со стороны государства. Банки неохотно выдают кредиты малым субъектам АПК ввиду сопутствующих высоких рисков. С учетом того что в настоящее время на рынке четко проявляется тенденция отзыва лицензий у кредитных организаций, проблема доступа к финансовым ресурсам для малых фрорм хозяйствования в АПК становится еще более острой. В связи с этим предлагаем рассмотреть альтернативные механизмы ффинансирования деятельности малых субъектов российского агропромышленного комплекса, одним из которых является кредитование peer-to-peer (P2P).

При написании статьи мы опирались на научные работы и прикладные разработки российских и зарубежных ученых и практиков по исследуемым проблемам в области финансового рынка в целом [2] и банковского рынка [3], рынка Р2Р-кредитования [4] в частности, а также в сфере особенностей и специфики трансформации агропромышленного комплекса в России [5].

Кредитование peer-to-peer подразумевает под собой кредитование одними физическими лицами других фризических лиц без участия традиционных для системы кредитования субъектов, таких как банки. Помимо физических лиц в данном процессе могут принимать участие индивидуальные предприниматели и юридические лица, однако преимущественно относящиеся к малым или микропредприятиям, поскольку сумма одной сделки чаще всего невелика. Р2Р-кредитование предполагает предоставление финансовых ресурсов на кратко- или среднесрочной основе. Необходимые денежные средства, которые заемщик хочет получить посредством механизма Р2P, могут быть аккумулированы сразу от нескольких заимодавцев.

Рассматриваемый вид кредитования технически реализуется с помощью интернет-площадки. Она выступает своеобразным рынком, где встречаются покупатель-заемщик и продавец- 
заимодавец. При этом одно и то же лицо может быть как заемщиком, так и заимодавцем. Наиболее характерным примером подобной площадки является WebMoney Transfer. Виртуальная площадка получает доход за счет комиссионных вознаграждений, которые могут быть установлены только для заемщиков или заимодавцев либо для них обоих. Комиссионные могут взиматься за оказание посреднических услуг по поиску контрагентов сделки.

Отдельной законодательной базы, регулирующей Р2Р-кредитование, в настоящее время в России нет. Такой подход, основанный на отсутствии специальных норм в рассматриваемой сфрере, достаточно оправдан, поскольку указанный механизм предоставления финансовых ресурсов может фрунционировать в рамках уже существующего и действующего на данный момент общегражданского законодательства. Создание специальной законодательной базы для Р2Р-кредитования излишне усложнит и так весьма непростое законодательное поле. Основным документом, регулирующим подобное кредитование, является Гражданский кодекс РФ, прежде всего положения ч. 2, касающиеся договора займа [6].

В целом принципы Р2Р-кредитования не отличаются от базовых принципов предоставления банковского кредита: платность, срочность, возвратность. На внедрение подобного кредитования в систему финансирования малых субъектов агропромышленного комплекса влияет ряд фракторов. Остановимся на наиболее специфических особенностях, присущих именно Р2P-кредитованию, при этом геополитические, общеэкономические и иные факторы, которые воздействуют на всю финансовую систему в целом, не входят в поле наших интересов.

Р2Р-кредитование нацелено преимущественно на краткосрочный период. Эта характеристика может как отталкивать малые формы хозяйствования в агропромышленном комплексе, так и привлекать их.

С одной стороны, малые субъекты АПК нуждаются в долгосрочных финансовых ресурсах для приобретения техники и иных дорогостоящих объектов. В этом случае им целесообразно обратиться в банк, который может предоставить кредит под залог имущества, учесть все нюансы работы организации, детально провести ее анализ и составить график погашения кредита с учетом сезонности производства, что особенно важно для сельскохозяйственных предприятий. Если малому субъекту необходимо профинансировать крупную сделку и получить кредит на длительный период, то Р2Р-кредитование проигрывает перед банковским предложением.

С другой стороны, малые формы хозяйствования в агропромышленном комплексе часто нуждаются в закрытии кассовых разрывов, приобретении оборотных активов с крайне быстрой оборачиваемостью (например, приобретении некоторых видов семян), а также в финансовых ресурсах в случае непредвиденных трат. Во всех этих ситуациях получить кредит от банка возможно, но ставка по нему будет достаточно высокой, поскольку очевидного объекта залога нет, а риски достаточно высоки с учетом целей, на которые будут использованы полученные средства. При этом целесообразно прибегнуть к Р2Р-кредитованию.

Также необходимо учесть, что банк, скорее всего, потребует стандартный, а возможно, и расширенный пакет документов для предоставления кредита, в то время как для заимодавцев в рамках Р2Р-кредитования достаточно минимального комплекта документов. С учетом того что малые формы хозяйствования в агропромышленном комплексе на практике представлены индивидуальными предпринимателями, микропредприятиями или малым бизнесом, имеющими особые условия налогообложения и предоставления бухгалтерской отчетности, зачастую они не способны в указанный банком срок собрать все необходимые документы.

Фактором, который может тормозить внедрение Р2Р-кредитования в систему финансирования в рамках агропромышленного комплекса, является проблема взыскания долгов с субъектов сделки, так как многие, преимущественно физические лица, боятся заключать договоры займа именно по этой причине. Действительно, обращение в коллекторские агентства стоит достаточно дорого, ведь они могут забрать 25 \% от суммы взыскания и даже более, что представляет существенную потерю для отдельного физического или юридического лица малого бизнеса или микропредпринимательства. С судебными тяжбами ситуация аналогична: они относительно дорого стоят и могут длиться очень долго, что делает их нерентабельными, а обращение в суд нецелесообразным. Исключить или нивелировать влияние данного обстоятельства на сегодня практически нельзя, поэтому оно по-прежнему будет негативно воздействовать на развитие финансовой системы российского АПК.

В классическом варианте интернет-площадка по Р2Р-кредитованию не предоставляет услуги по обслуживанию долга, что для некоторых заемщиков и заимодавцев может стать негативным фактором и препятствовать внедрению рассматриваемого механизма в систему финансирования малых субъектов агропромышленного комплекса. Тем не менее в настоящее время современные малые субъекты имеют в штате или на аутсорсинговой основе специалистов, которые могут сво- 
бодно обращаться с финансовыми документами в электронном виде и проводить электронные платежи, ведь обязательная к представлению в налоговые и иные государственные органы финансовая и иная отчетность уже передается в электронном виде. Таким образом, указанный негативный фактор если и повлияет на участников российского АПК, то только на крайне малое их число и не будет тормозить развитие альтернативных механизмов его финансирования.

Одним из конкурентов для площадок, предоставляющих услуги по реализации Р2Р-кредитования, являются микрофинансовые организации. Однако в настоящее время их репутация сильно испорчена из-за ряда обстоятельств, начиная от запредельно высоких процентов по займам до некорректного обращения в коллекторские агентства и возникающих после этого судебных процессов. Такая рыночная ситуация только способствует развитию рассматриваемого механизма, который сводит риски обращения в сомнительные коллекторские агентства практически до нуля, ведь кредиторами являются преимущественно физические лица, а полученные малыми субъектами агропромышленного комплекса займы чаще всего предоставляются несколькими разными, не связанными между собой заимодавцами. Это содействует повышению доверия экономических субъектов к Р2Р-кредитованию.

Негативным фрактором, тормозящим развитие данного вида кредитования в России и его активное внедрение в рамках фринансирования малых субъектов хозяйствования агропромышленного комплекса, является крайне низкий уровень финансовой грамотности населения, которое не столько не желает воспользоваться всеми возможными инструментами и механизмами финансового рынка, сколько не знает о них. К сожалению, нивелировать влияние указанного отрицательного обстоятельства возможно только в долгосрочной перспективе при поддержке со стороны государства, путем повсеместного проведения курсов по повышению финансовой грамотности граждан.

Развитие интернет-банкинга способствует внедрению Р2Р-кредитования, ведь активные пользователи сети уже привыкли получать финансовые услуги быстро, качественно и без лишних временных затрат, а значит, могут достаточно быстро понять и оценить предлагаемый механизм с точки зрения его «бытового» удобства. Сейчас во главе малых субъектов агропромышленного комплекса стоят современные руководители, которые отлично ориентируются в интернет-пространстве. Площадки Р2Р-кредитования не только не оттолкнут их своей технической составляющей (которая в большинстве случае имеет простой и интуитивно понятный интерфейс), но и заинтересуют удобством предоставления услуги и возможностью отслеживать все сделки и операции в режиме реального времени. Кроме того, можно отметить, что физические лица помимо коммерческой выгоды в виде процентной ставки по займу могут получать еще и социальные преимущества и удовлетворение от фринансирования посредством Р2Р-кредитования одного из наиболее значимых секторов экономики - агропромышленного комплекса, снабжающего население продуктами питания, что выступает еще одним положительным фактором.

В целом, несмотря на присутствующие негативные факторы внедрения рассматриваемого механизма в систему финансирования малых субъектов российского АПК, нет никаких непреодолимых препятствий, которые мешали бы малым формам хозяйствования воспользоваться возможностью получения фринансовых ресурсов альтернативным образом - посредством Р2Р-кредитования. Предлагаемый нами механизм является более доступным и гибким, нежели банковские продукты, и при этом выгоден с коммерческой и некоммерческой точек зрения как заемщику, так и заимодавцу.

Несмотря на достаточно широкие, а в некоторых секторах финансового рынка даже расширяющиеся, возможности получения фринансовых ресурсов для малых фрорм хозяйствования в агропромышленном комплексе России, проблема финансирования не теряет остроты. Новые институты, инструменты и механизмы, способствующие ее решению, могут пользоваться популярностью и прочно входить в финансовую систему. Одним из таких способов финансирования малых субъектов АПК мы считаем Р2Р-кредитование.

В дальнейшем востребованность данного вида займов для малых субъектов агропромышленного комплекса может повыситься не только за счет ряда преимуществ, но и на фоне общеэкономической нестабильности, недоверия к микрофинансовым организациям, сокращения количества банков на рынке, а также ужесточения требований к их деятельности, что сразу сказывается на регрессном ужесточении требований к заемщикам. Таким образом, механизм Р2P-кредитования позволит малым формам хозяйствования в российском АПК расширить возможности привлечения финансовых ресурсов.

\section{Ссылки и примечания:}

1. Работа выполнена при финансовой поддержке ФГБОУ ВО «РЭУ им. Г.В. Плеханова».

2. Миркин Я. Циклы глобальных финансов // Проблемы теории и практики управления. 2016. № 6. С. 51-56 ; Слепов В.А., Чалова А.Ю. Источники финансирования экономического роста в России: проблемы и перспективы // Научный бюллетень Российского экономического университета им. Г.В. Плеханова. М., 2017. С. $170-176$. 
3. Лаврушин О.И. Новые явления в развитии кредита и институциональной структуре банковского сектора // Банковское дело. 2017. № 2. С. 14-19; Новое прочтение теории кредита и банков : коллективная монография / под ред. И.В. ЛариОновой. М., 2017.

4. Патласов О.Ю., Грахов А.А. Краудфандинг и сеть Р2P: прогноз взаимодействия и альтернативного финансирования в условиях кризиса // Наука о человеке: гуманитарные исследования. 2016. № 4 (26). С. 204-218 ; Тетерятников К.С. Платфрормы P2P как инструмент альтернативного финансирования: международный и российский опыт // Менеджмент и бизнес-администрирование. 2015. № 2. С. 109-119; Mach T.L., Carter C.M., Slattery C.R. Peer-to-peer lending to small businesses // Finance and Economics Discussion Series. Federal Reserve Board. 2014. November. P. 26.

5. Гайсин Р.С. Особенности формирования цен, спроса, предложения на агропродовольственном рынке России // Феномен рыночного хозяйства: от истоков до наших дней : материалы III Междунар. науч.-практ. конф. Краснодар, 2015. C. 473-484 ; Maksimova T.P., Bondarenko N.E. Development of inter-firm cooperation in the Russian agro-industrial complex: theory and practice // Espacios. 2017. Vol. 38, no. 33. P. 15.

6. Гражданский кодекс Российской Федерации [Электронный ресурс] : от 26 янв. 1996 г. Ч. 2. Доступ из справ.-правовой системы «КонсультантПлюс».

\section{References:}

Gaysin, RS 2015, 'Prices, demand, supply creation on the agrifood market of Russia', Fenomen rynochnogo khozyaystva: ot istokov do nashikh dney: materialy III Mezhdunar. nauch.-prakt. konf., Krasnodar, pp. 473-484, (in Russian).

Larionova, IV (ed.) 2017, A new vision of the theory of credit and banks: a collective monograph, Moscow, (in Russian).

Lavrushin, Ol 2017, 'New phenomena in the development of credit and institutional structure of the banking sector', Bankovskoye delo, no. 2, pp. 14-19, (in Russian).

Mach, TL, Carter, CM \& Slattery, CR 2014, 'Peer-to-peer lending to small businesses', Finance and Economics Discussion Series. Federal Reserve Board, November, p. 26.

Maksimova, TP \& Bondarenko, NE 2017, 'Development of inter-firm cooperation in the Russian agro-industrial complex: theory and practice', Espacios, vol. 38, no. 33, p. 15

Mirkin, Ya 2016, 'Global finance cycles', Problemy teorii i praktiki upravleniya, no. 6, pp. 51-56, (in Russian).

Patlasov, OYu \& Grahov, AA 2016, 'Crowdfunding and P2P network: prediction of interaction and alternative funding in crisis', Science of the Person: Humanitarian Researches, no. 4 (26), pp. 204-218. https://doi.org/10.17238/issn19985320.2016.26.204.

Slepov, VA \& Chalova, AYu 2017, 'Sources of financing of economic growth in Russia: problems and prospects', Nauchnyy byulleten' Rossiyskogo ekonomicheskogo universiteta im. G.V. Plekhanova, pp. 170-176, (in Russian).

Teteryatnikov, KS 2015, 'P2P platforms as an alternative financing tool: international and Russian experience', Menedzhment i biznes-administrirovaniye, no. 2, pp. 109-119, (in Russian). 